\title{
The technology of curd cake with sucralose: a infrared spectroscopy analysis
}

\author{
Olena Aksonova ${ }^{1 *}$, Sergey Gubsky ${ }^{1}$, Dmitry Torianik ${ }^{1}$ and Victoria Evlash ${ }^{1}$ \\ ${ }^{1}$ Educational and Research Institute of Food Technology and Business, Kharkiv State University of food technology and trade, \\ Kharkiv, Ukraine
}

\begin{abstract}
The article presents the results of developing technology for the production of curd cake using a low-calorie sweetener sucralose. The implementation of this direction in the form of a partial replacement in the sugar formulation for effective sweeteners sucralose is proposed. As a prototype, a sugar-based recipe was used, in which a partial replacement (at the level of $50 \%$ ) of sugar with sucrose was carried out. Sucralose was formulated as the commercial sweetener TM Splenda, which contains maltodextrin and sucralose. All samples, including the control on sugar, were subjected to organoleptic evaluation, which showed the absence of extraneous flavors in all samples and their similarity in terms of sweetness compared to control. IR spectra of the sweetener, curd cake with sugar, as well as curd cakes with $50 \%$ and $100 \%$ sugar substitution for sweetener were obtained and analyzed. The analysis showed the presence of identical characteristic bands on the spectra of the sweetener and samples of sucralose cakes, which suggests that the sweetener TM Splenda does not undergo thermal degradation when baking curd cake. However, the literature analysis indicates the danger of the formation of toxic gaseous substances that are obtained during the thermal treatment of products with sucralose.
\end{abstract}

\section{Introduction}

The global trend of an increase in the incidence of diabetes among the population and the emergence of a high percentage of overweight people are prompting the food industry to develop recipes for low-sugar flour confectionery or to completely replace it with highly effective sweeteners [1].

The wide range of sweeteners and the growing attention to them are explained by their significant economic advantages in relation to sugar, since they all have a sweetness coefficient much higher than that of sucrose and are easy to use. [2]. In general, they can be conditionally divided into two groups in terms of use in food technologies. Substances with almost "zero calories" and very intense sweet taste, which are used in small quantities to replace the sweetness of much higher amounts of sugar and are approved for use in the food industry, can be classified in the first group. The second group includes caloric substances that can replace both physical mass and the sweetness of sugar. Products of this type, sometimes referred to as "sugar replacers"or "bulk sweeteners," include the sugar alcohols (also called "polyols").

Sucralose belongs to the sugar substitutes of the first group. From a chemical point of view is a chloroderivative of sucrose and is known as the food additive E955. It is about 600 times sweeter than sugar but, this factor varies depending on the level of sucralose being used. Like sugar, sucralose is a white, crystalline, nonhygroscopic, free-flowing powder and freely soluble in water.
This sweetener has a zero glycemic index and zero caloric content. Although sucralose is made from sugar, the human body does not recognize it as a sugar and does not metabolize it; therefore, it provides sweetness with no calories. Sucralose was approved as a food additive in USA, Canada, UK and European countries, followed by others. It is on sale as a product under the trademark SPLENDA ${ }^{\circledR}$ (Brand Sweetener of Tate \& Lyle PLC, UK), which also includes other related components. Flour confectionery, and in particular cheese cake, are in demand among consumers. And the development of a technology for the production of cheese cake with a partial replacement of sugar with sucralose is relevant for solving the problems of overweight and preventing type 2 diabetes. Earlier [3] we offered technology of curd cake with suclarose as sweetener. The organoleptic analysis of the obtained samples showed that the sweetness levels for sugar curd cake with and sucralose curd cake areidentical. This fact indirectly indicates the thermal stability of the sweetener used in the technology.

This technology was based on an approach with partial replacement of sugar with sucralose. In the process of optimizing this technology, two problems were identified. The first is related to the need for compensation of effect of added sugar on food quality. It is known that sugar is a structure-forming component [4]. This problem was solved by adding more formulation ingredients (curd). This procedure increased the amount of solids, the amount of which was reduced by partial replacement of sugar. The second problem was related to the safety of using sucralose in this technology, which requires a baking temperature of $170^{\circ} \mathrm{C}$ to prepare the 
product. This sweetener is known to be thermally stable up to temperatures $120{ }^{\circ} \mathrm{C}$ [1]. With regard to the behavior of sucralose as the temperature rises further, many questions arise about its ability to form chlorinated by-products. This issue has been studied in detail in numerous original research [5-9] and review papers [10, 11].

Table 1 provides an overview of some of the research on the thermal decomposition of sucralose. In most publications, the object of these studies is pure sucralose. Only in work [5] real samples of food with sucralose were investigated. However according [8], these results lack credibility due to inefficient separation technique with thin-layer chromatography used in analysis of degradation products.

Most research suggests that thermal decomposition of Sucralose is associated with the release of chlorides, leading to the formation of possibly harmful compounds [11]. The most detailed analysis on this issue was carried out on the basis of literature data in [10]. According to this review, available data indicate that harmful compounds, some of which are carcinogenic, can occur when sucralose, and especially foods containing sucralose such as canned vegetables or baked goods, are heattreated. When sucralose is heated to temperatures above $120^{\circ} \mathrm{C}$, the sweetener gradually decomposes and dechlorinates. Temperatures of $120-150^{\circ} \mathrm{C}$ are possible during industrial food production and processing, and are also reached in private households during the preparation and baking of foods containing sucralose. This can lead to the formation of potentially hazardous chlorinated organic compounds such as polychlorinated dibenzo-pdioxins (PCDD), dibenzofurans (PCDF) and chloropropanols. However, there are currently insufficient data for final conclusions.

The data in Table 1 indicate that the spectroscopic method in the infrared region was used as one of the most common experimental physicochemical methods for studying the decomposition products of sucralose. Fourier transform infrared spectroscopy is a powerful as a primary tool that facilitates the study of materials in matrix of foods. The technique allows monitoring the changes in various chemical bonding compounds. On the other hand, FTIR spectroscopy can be used as the technique of complementary measurement to help interpret the results along with other techniques. This determined the choice of the method in this work, the purpose of which was to study the possibility of the safe use of sucralose as a sweetener in the production of baked goods using the example of curd cake production.

Table 1. Study of thermal degradation of sucralose

\begin{tabular}{|c|c|c|c|}
\hline Samples & Method & Results & References \\
\hline $\begin{array}{l}\text { Baked goods } \\
\text { (yellow cake, } \\
\text { cookies, } \\
\text { graham } \\
\text { crackers) with } \\
\text { radioactively } \\
{ }^{14} \text { C- marked } \\
\text { Sucralose }\end{array}$ & $\begin{array}{l}\text { Radiolabeling techniques } \\
\text { (by liquid scintillation), } \\
\text { thin-layer } \\
\text { chromatography }\end{array}$ & $\begin{array}{l}\text { a. Sucralose minimally degrades in baked goods in range } 180-300^{\circ} \mathrm{C} \text {. } \\
\text { b. The marked Sucralose did not react with any other ingredients in the } \\
\text { baked goods. } \\
\text { c. The authors concluded that Sucralose is "heat-stable" }\end{array}$ & {$[5]$} \\
\hline $\begin{array}{l}\text { Sucralose in } \\
\text { buffered } \\
\text { solutions at } \\
\text { pH } 3,7 \text {, and } \\
11\end{array}$ & $\begin{array}{l}\text { High performance liquid } \\
\text { chromatography, } \\
\text { Ionmetry using a chloride } \\
\text { selective electrode }\end{array}$ & $\begin{array}{l}\text { a. The biggest change appeared to occur after } 120^{\circ} \mathrm{C} \text { and at temperatures } \\
\text { up to } 140^{\circ} \mathrm{C} \text {, there was a greater amount of chloride released at all three } \\
\mathrm{pH} \text { levels } \\
\text { b. The largest class of compounds produced was furans. } \\
\text { c. The compound produced in the highest amounts was levulinic acid. }\end{array}$ & {$[6]$} \\
\hline $\begin{array}{l}\text { Sucralose } \\
\text { with assay }> \\
98.0 \% \text { (HPLC } \\
\text { - grade) }\end{array}$ & $\begin{array}{l}\text { Differential scanning } \\
\text { calorimetry, } \\
\text { thermogravimetric } \\
\text { analysis, infrared (IR) } \\
\text { spectroscopy }\end{array}$ & $\begin{array}{l}\text { a. The sucralose is thermally stable up to } 119^{\circ} \mathrm{C} \text { and above this } \\
\text { temperature the thermal decomposition takes place in three steps up to } \\
5500^{\circ} \mathrm{C} \text { and without melting. } \\
\text { b. The endothermic peak at } 131^{\circ} \mathrm{C} \text { (thermogravimetric analysis) and } \\
128^{\circ} \mathrm{C} \text { (differential scanning calorimetry) is due to the thermal } \\
\text { decomposition with release of constitution water and hydrogen chloride. } \\
\text { c. IR spectra also confirm that the thermal decomposition occurs above } \\
119^{\circ} \mathrm{C}\end{array}$ & [7] \\
\hline Sucralose & $\begin{array}{l}\text { Pyrolysis-gas } \\
\text { chromatography-mass } \\
\text { spectrometry }\end{array}$ & $\begin{array}{l}\text { a. Degradation of sucralose and glucose may generate a levoglucosenone } \\
\text { a well documented degradation product. } \\
\text { b. Caution should be exercised in the use of sucralose as a sweetening } \\
\text { agent during baking of food products containing lipids due to the } \\
\text { potential formation of toxic chloropropanols. }\end{array}$ & [8] \\
\hline $\begin{array}{l}\text { Technical- } \\
\text { grade } \\
\text { sucralose }\end{array}$ & $\begin{array}{l}\text { Differential scanning } \\
\text { calorimetry, } \\
\text { thermogravimetric } \\
\text { analysis, } \\
\text { IR spectroscopy, } \\
\text { hot-stage microscopy, } \\
\text { high-resolution mass } \\
\text { spectrometry }\end{array}$ & $\begin{array}{l}\text { a. Decomposition of sucralose happens around } 125^{\circ} \mathrm{C} \text { in form of carbon } \\
\text { dioxide along with the formation of hydrogen chloride and other minor } \\
\text { compounds. } \\
\text { b. Chlorinated derivatives, including polychlorinated aromatic } \\
\text { hydrocarbons were confirmed. } \\
\text { c. These findings not only corroborate the suspected instability of } \\
\text { sucralose to high temperatures, but also indicate that even exposed to } \\
\text { mild conditions the formation of hazardous polychlorinated compounds } \\
\text { is observed. }\end{array}$ & [9] \\
\hline
\end{tabular}




\section{Experimental}

\subsection{Materials}

The ingredients used in this study obtained from local stores in city Kharkiv, Ukraine. sucralose as SPLENDA TM was purchased from tate\&lyle plc, uk and used was food grade. according to the manufacturer's information on the packaging, the sweetener contains maltodextrin (id) and sucralose (according to information available on the internet, the content of sucralose is $1 \%$ ). potassium bromide (reachim, russia) used was analytical grade.

\subsection{Sampling}

A curdcake was manufactured according to [3]. The product included wheat flour, butter, milk cheese $9 \%$, melange and baking powder. In the production of curdcake was used sucralose in the form of sweetening SPLENDA TM. The manufacturer of this brand states that the product contains not only sucralose but also maltodextrins. The full chemical composition in percentage on the package is not indicated. However, according to literature data, this product contains $1 \%$ sucralose. Therefore, a sweetener based in sucralose was added based in a partial (50\%) and full (100\%) sugar substitute in and amounted to 0.10 and $0.05 \mathrm{~g}$, respectively. Cheese cakes samples with a mass of $100 \mathrm{~g}$ were baked in silicone forms at a temperature of $170^{\circ} \mathrm{C}$ for 30 minutes.

The samples obtained using this technology were designated as S50 and S100, respectively, for curd cake with $50 \%$ and $100 \%$ sugar substitution. The prototype on sucrose sample was considered in the study as Control.

\subsection{Methods}

Fourier transform infrared coupled to attenuated total reflectance (ATR-FTIR) spectra of curd cake samples were obtained using Nicolet iS5 FT-IR spectrometer with the versatile iD5 ATR Accessory (Thermo Scientific, USA) as the result of the accumulation of 32 scans with a resolution of $4 \mathrm{~cm}^{-1}$ in the range of $4000-600 \mathrm{~cm}^{-1}$.

FTIR spectra of SĐLENDA were recorded between 4000 and $400 \mathrm{~cm}^{-1}$ using a the same spectrometer with Thermo Scientific Base Adapter in a potassium bromide matrix. Discs of matrix were prepared by first mixing 0.5 $\mathrm{mg}$ of dried sample with $500 \mathrm{mg}$ of $\mathrm{KBr}$ in an agate mortar and then pressing the resulting mixture. A pellet containing only potassium bromide was prepared and used as the reference sample for transmission measurements.

Each spectrum was converted to ASCII format to be further processed. Processing of spectroscopic data obtained including spectral pretreatment (correction of baseline, ATR correction and correction for ambient carbon dioxide, smooth of spectra) were performed with the Know It All Informatics System 2020, Academic Edition (John Wiley\&Sons Inc., USA) software.

\section{Results and discussion}

Obtained in the FTIR spectra of the sweetener TM SPLENDA is given on Fig. 1. As already mentioned, the sweetener contains maltodextrin and sucralose, and the content of maltodextrin is approximately one hundred times higher than that of sucralose. Thus, it was maltodextrin that made the main contribution to the obtained results. Based on literature data [12], the spectrum for MD exhibited a strong broad absorption band centered at $3300 \mathrm{~cm}^{-1}$ and a weak band at $\sim 1635$ $\mathrm{cm}^{-1}$ which arise from $\mathrm{OH}$-stretching and $\mathrm{OH}$-bending (in plane) modes, respectively. An absorption band of $\mathrm{CH}$ stretching vibrations was found at $2900 \mathrm{~cm}^{-1}$. The spectrum of the sweetener shows that the broad intense band observed for maltodextrin at $3300 \mathrm{~cm}^{-1}$ is shifted to $3420 \mathrm{~cm}^{-1}$. An upward shift is also observed for the band corresponding to $\mathrm{CH}$-stretching absorption band $2930 \mathrm{~cm}^{-1}$. The shift of these bands can be explained by the presence of sucralose, which contains chlorine atoms, which, possibly, affect the redistribution of electron density within the molecule and reduce the possibility of the formation of intra- and intermolecular bonds for hydroxyl groups. A weak band at $1635 \mathrm{~cm}^{-1}$ is observed on the spectrum of the sweetener as well as on the spectrum of pure MD.

The results of studies indicate the existence in the spectrum of characteristic bands of $635 \mathrm{~cm}^{-1}$, which correspond to strength vibrations of the $\mathrm{C}-\mathrm{Cl}$ bond in the sucralose molecule [13]. It is this band that makes it possible to identify sucralose in the composition of the sweetener.

The spectra of samples Control, S50 and S100 are shown in Fig. 2. The contribution of water to the formation of the $\mathrm{OH}$-stretching absorption band in carbohydrate-water systems is very strong. In these systems clusters of water molecules could be categorized into three families according to their hydrogen bond organization. The first, originating from tetrahedrally bonded water molecules, namely networking water, locates in the region of around $3300 \mathrm{~cm}^{-1}$ to $3314 \mathrm{~cm}^{-1}$. The second is intermediate water, which is a weakly or distorted hydrogen bonded family locates at around 3441 to $3470 \mathrm{~cm}^{-1}$. The last family is free or multimer water, which originates at around 3570 to $3610 \mathrm{~cm}^{-1}$ from water monomers and dimers and locates [14-16].

The spectra of cake samples have bands with peaks at $3275 \mathrm{~cm}^{-1}$ - Control, $3281 \mathrm{~cm}^{-1}$ - S50 and $3355 \mathrm{~cm}^{-1}$ for $\mathrm{S} 100$, which indicates that water in the product, is mainly in the form of networking water (Fig.3).

It should also be noted the shift of this band to the region of large values with increasing concentration of the sweetener. For sample S100, this value is already $3355 \mathrm{~cm}^{-1}$, which is very close to the indicator of this band in the spectrum of pure sweetener $3420-3420 \mathrm{~cm}^{-1}$. This again speaks in favor of the fact that the sweetener is preserved during heat treatment. In addition, the water begins to change to the state intermediate water weakly or distorted hydrogen bonded. 
The spectra next from the fingerprint region, in the range of 1800 to $1600 \mathrm{~cm}^{-1}$, which usually arise from $\mathrm{H}$ $\mathrm{O}-\mathrm{H}-$ bending of water molecules [17]. Thus, the bands in the range of $1650-1630 \mathrm{~cm}^{-1}$ can be attributed to water of crystallization, and the spectra clearly show the dependence between the sugar content and the amount of water of crystallization: in a sample with $100 \%$ sugar replacement by sweetener, this band is the most intense,
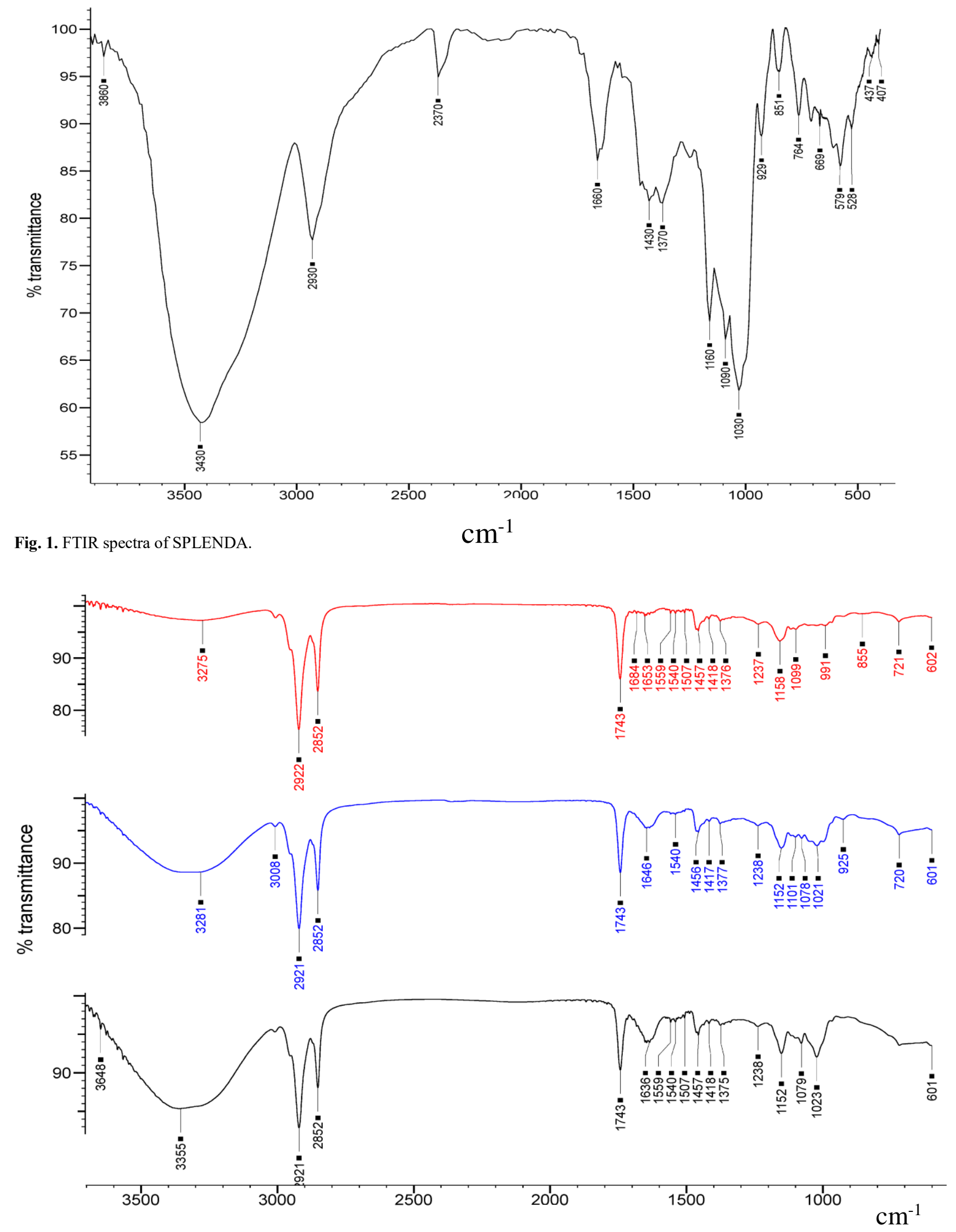

Fig. 2. Representative ATR-FTIR spectra in the fingerprint region of the curd cake samples: control (red), S50 (blue) and S100 (black) 
and in the sample with sugar it is practically absent (Fig 2).

This region of 1800 to $800 \mathrm{~cm}^{-1}$ the so called a "fingerprint" region. Vibrations in this region are mainly attributed to in-ring $\mathrm{CO}$-stretching, interring $\mathrm{COC}-$, $\mathrm{COH}$ - and $\mathrm{CCH}$ - bending, and symmetrical deformations of $\mathrm{CH}_{2}$ groups. Vibrations of $1035-1030 \mathrm{~cm}^{-1}$ are identified as aromatic $\mathrm{C}-\mathrm{H}$ planar bending vibrations. This band is clearly visible on the sweetener spectrum.

It is absent in the spectrum of the sample with sugar, and in the spectra of samples on sucralose this band is shifted to a lower region $-1021 \mathrm{~cm}^{-1}$ and $1023 \mathrm{~cm}^{-1}$ for samples S50 and S100, respectively (Fig. 2). This fact may also be a reason to think that the sucralose molecule has not undergone thermal degradation.

However, one should take into account the risks of the appearance of substances hazardous to health during the heat treatment, which can also be identified using IR spectra. Most studies suggest that thermal decomposition of Sucralose is associated with the release of chlorides, resulting in the formation of possibly harmful compounds $[11,18]$

It should be noted, that in the obtained spectra of samples of curd cake with sucralose, peaks at $1743 \mathrm{~cm}^{-1}$ are observed. These peaks, as in [7], can be attributed to the carbonyl stretching frequency appeared after heated the sample is up to $130^{\circ} \mathrm{C}$. However, these peaks may not necessarily be associated with the degradation of sucralose, most likely the thermal transformation of other nutrients present in the formulation also contributes to their appearance. This fact is also confirmed by the fact that the same band is present in the spectrum of the "control" sample, in the production of which sucralose was not used. Therefore, rather, this band can be explained by the occurrence of the Maillard reaction.

The results of FTIR analysis presented in [9] show that at the point of decomposition of sucralose one can observe characteristic profiles of water (ranges from 4000-3200 $\mathrm{cm}^{-1}$ and 2000-1200 $\mathrm{cm}^{-1}$ ), carbon dioxide (the main peak at 2400-2300 $\mathrm{cm}^{-1}$ ), hydrogen chloride (range from 3100-2600 $\mathrm{cm}^{-1}$ ) and chloroacetaldehyde (main peak at 1850-1700 $\mathrm{cm}^{-1}$ ). However, such a complex system as curd cake requires water. As for the bands that can be attributed to carbon dioxide, they were not found in the finished product. The latter suggests that the identification of $\mathrm{CO}_{2}$ is relevant when studying the thermal decomposition of pure sucralose. In such complex systems as food systems, it is not correct to conclude that sucralose decomposes by the presence of peaks that can be attributed to $\mathrm{CO}_{2}$. The peak attributed to chloroacetaldehyde may also be associated with a carbonyl group, which does not have to be part of chloroacetaldehyde. For example, the Maillard reaction leads to the formation of numerous pore products with a rather complex and often unknown structure, among which there are compounds containing a carbonyl group. In addition, the $1850-1700 \mathrm{~cm}^{-1}$ region can be associated with a number of carbonyl compound group frequencies [19].

Among the compounds hazardous to health that can appear in food during the thermal decomposition of sucralose, there may also be: chloropropanols, PCDD and PCDF congeners and dioxin-like polychlorinated biphenyls (dl-PCBs), Polychlorinated naphthalene (PCN) congeners. However, it should be noted that chloropropanols in the study [8] were found in the

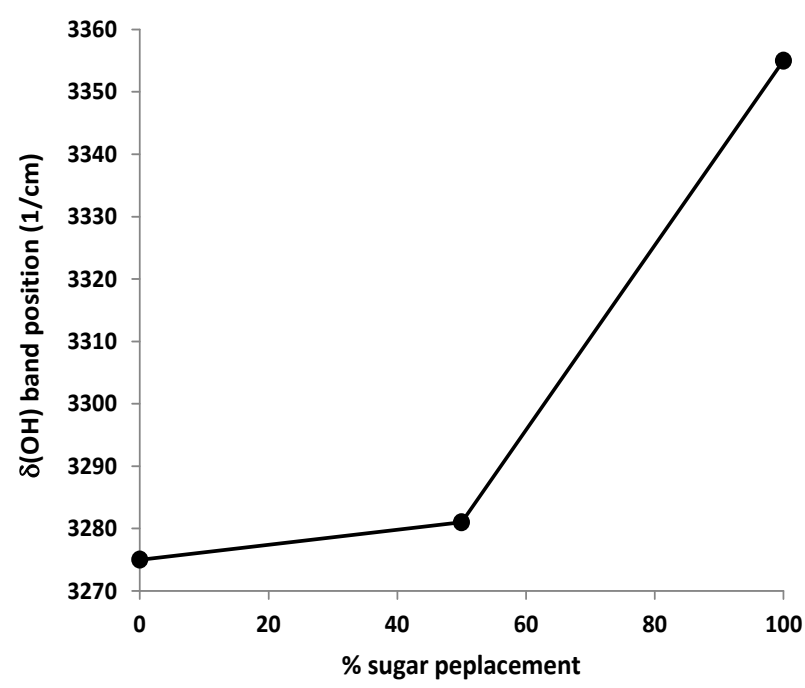

Fig. 3. Band positions of $\mathrm{OH}$-stretching vibration for curd cake samples

released gas phase.

The authors [20] concluded that the heating (roasting) of Sucralose in the presence of soybean oil and beef at $250^{\circ} \mathrm{C}$ led to the formation of various toxic PCDF and PCDD congeners which were transferred from the solid to the gas phase. Moreover, they emphasized that it is important to ensure effective ventilation when cooking with Sucralose in order to reduce the exposure risk of consumers to the occurring volatile PCDFs and PCDDs via inhalation.

The authors concluded that, due to thermal decomposition during heating (roasting) to $160^{\circ} \mathrm{C}$ in the presence of soybean oil and beef, Sucralose became a source of chloride, which in turn promoted the formation of dl-PCB compounds, which were finally found in the oil vapors. They also hypothesised that an "appropriate" use of chloride-containing additives during cooking could therefore help to reduce exposure of consumers to dlPCBs [21].

In [22] it is said that that heating of Sucralose together with peanut or olive oil free of PCN, can lead to the formation of various PCN congeners as well as PCDD, PCDF and PCB compounds, which were released with the vapors generated during the further course of the process.

It should be noted separately that most of the studies in which the thermal degradation of sucralose was studied were carried out at temperatures above $200^{\circ} \mathrm{C}$. These temperatures are significantly higher than those used in baked goods technologies. You should also pay attention to studies on the study of the temperature gradient in baked goods during their production [23-25]. So the author of [23] showed that the temperature of the central layers of biscuit crumb is $97-98^{\circ} \mathrm{C}$ at the end of baking. Similar studies for muffins [24] indicate a temperature at 
the end of baking of $103-104{ }^{\circ} \mathrm{C}$. The crumb temperature at the end of baking for muffins was $100-101^{\circ} \mathrm{C}$, which was reached for muffins on sucrose in 25 minutes, and on fructose in 23 minutes [25].

In the same work, the authors noted that the temperature in the samples during baking does not exceed the decomposition temperature of sucralose. But on the surface, the temperature rises to $120^{\circ} \mathrm{C}$ for 12 minutes of baking for muffins on sucrose and from 12 to 24 minutes of baking - up to $160^{\circ} \mathrm{C}$ at a working chamber temperature of $180^{\circ} \mathrm{C}$. Thus, we can conclude that the thermal decomposition of sucralose during the manufacture of curd cake does not occur, although it cannot be ruled out that part of sucralose is involved in thermal degradation. It should also be noted that the issue of products generated during this process remains open and requires integrated approaches.

\section{Conclusion}

An analysis of the literature showed that Sucralose is dechlorinated and this may lead to the formation of chlorinated organic compounds with possibly harmful potential (e.g. polychlorinated dibenzo-para-dioxins or dibenzofurans or chlorpropanols). The literary analysis also showed that, it can be concluded that substances hazardous to humans were detected in the gas phase formed during the heat treatment of the food product, and were not identified in the finished product using the analysis of IR spectra. Moreover, most of the research has been conducted at temperatures higher than those used to make curd cake.

Based on the currently available data, it is impossible to judge the degree of formation of toxicologically significant congeners and to attribute them directly to the presence of sucralose. Since the ongoing Maillard reactions lead to the formation of not only dioxins, but also other potentially toxic compounds.

The spectra of cake samples have bands with peaks in range $3275-3355 \mathrm{~cm}^{-1}$, which indicates that water in the product is mainly in the form of networking water. A shift of this band to the region of large values is observed with an increase in the concentration of the sweetener. For sample S100, this value is already $3355 \mathrm{~cm}^{-1}$, which is very close to the indicator of this band in the spectrum of pure sweetener $-3420 \mathrm{~cm}^{-1}$. This once again speaks in favor of the fact that the sweetener is preserved during heat treatment.

The spectra of samples of curd cakes with sucralose have peaks in the range of $1035-1030 \mathrm{~cm}^{-1}$, which are identified as aromatic $\mathrm{C}-\mathrm{H}$ planar bending vibrations. This band is clearly visible on the sweetener spectrum. It is absent in the spectrum of the sample on sugar, but in the spectra of samples on sucralose this band is shifted to a lower region. This also suggests that the sweetener has not undergone thermal degradation. This also indicates that chlorine is in a bound state, and this indicates the impossibility of forming substances hazardous to human health.

Analysis of IR spectra cannot be proposed as a $100 \%$ reliable method for identifying potentially hazardous substances in food (chloropropanols, polychlorinated dibenzo-para-dioxins, polychlorinated dibenzofurans congeners, dioxin-like polychlorinated biphenyls and polychlorinated naphthalene congeners).

The presented results indicate that further studies of the thermal behavior of sucralose in food products are needed using a combination of physicochemical methods. Moreover, both the final product and the products that are obtained at different stages of heat treatment should be investigated.

\section{References}

1. K. O’Donnell, M.W. Kearsley, (eds.), Sweeteners and Sugar Alternatives in Food Technology (Second Ed., Oxford: Wiley-Blackwell, 2012).

2. L. O'Nabors, Alternative Sweeteners (Boca Raton: CRC Press 2012).

3. O. Aksonova, S. Gubsky, D. Torianik, N. Murlykina, Progressive Technique and Technologies of Food Production Enterprises, Catering Business and Trade, 1, pp. 7 (2020).

4. R. A. Clemens, J. M. Jones, M. Kern, S.-Y. Lee, E. J. Mayhew, J. L. Slavin, and S. Zivanovic, Comprehensive Reviews in Food Science and Food Safety, 15, pp. 433 (2016).

5. R.L. Barndt, G. Jackson, Food Technology (Chicago), 44, pp. 62 (1990).

6. S.A. Hutchinson, S.Ho Gregory and Ho Chi-Tang, Food Reviews International, 15, pp. 249 (1999).

7. G. Bannach, R. R. Almeida, L. G. Lacerda, E. Schnitzler, and M. Ionashiro, Eclética Química, 34, pp. 21 (2009).

8. A. Rahn, A.Ya. Varoujan, Food Chemistry, 118, pp. 56 (2010).

9. D. N. de Oliveira, Maico de Menezes, and Rodrigo R. Catharino, Scientific Reports, 5, pp. 1 (2015).

10. BfR - Bundesinstitut für Risikobewertung. 2019. "Harmful Compounds Might Be Formed When Foods Containing the Sweetener Sucralose Are Heated," BFR (No 012/2019):1-22.

11. S.S. Schiffman, K. I. Rother, Journal of Toxicology and Environmental Health - Part B: Critical Reviews, 6, pp. 399 (2013).

12. E. Sritham, S. Gunasekaran, Food Hydrocolloids, 70, pp. 371 (2017).

13. B. Guven, S. D. Velioglu, I. H. Boyaci, Gida, The Journal of Food, 44, pp. 274 (2019).

14. M.E. Gallina, P. Sassi, M. Paolantoni, A. Morresi, and R. S. Cataliotti, The Journal of Physical Chemistry B, 110, pp. 8856 (2006).

15. A. Lerbret, P. Bordat, F. Affouard, Y. Guinet, A. Hédoux, L. Paccou, D. Prévost, and M. Descamps, Carbohydrate Research, 340, pp. 881 (2005).

16. J. Malsam, A. Alptekin, The Journal of Physical Chemistry B, 113, pp. 6792 (2009). 
17. A. Gharsallaoui, B. Rogé, J. Génotelle, M. Mathlouthi, Food Chemistry, 106, pp. 1443 (2008).

18. S. S. Schiffman, Chemical Senses, 37, pp. 671 (2012).

19. J. Coates, Encyclopedia of Analytical Chemistry. Chichester (UK: John Wiley \& Sons, Ltd., 2006)

20. J. Wu, S. Dong, G. Liu, B. Zhang, M. Zheng, Journal of Agricultural and Food Chemistry, 59, pp. 5444 (2011).

21. S. Dong, J. Wu, G. Liu, B. Zhang, M. Zheng, Food Control, 22, pp. 1797 (2011).
22. A. Fernandes, M. Rose, J. Falandysz, Environment International, 104, pp. 1 (2017).

23. E. Bondarenko, Studies of the Kinetics of the Biscuit Baking Process Semi-Finished Products (Kiyv: KTIFI, 1979).

24. V. V. Dorokhovich, Development of rational technologies of diabetic flour confectionery products based on fructose (Kiyv: NUFT, 2000).

25. A. Dorokhovich, N. Lazarenko, Progressive Technique and Technologies of Food Production Enterprises, Catering Business and Trade, 1, pp. 414 (2012). 